\title{
FATORES DE IMPACTO NO SUCESSO DO MARKETING BOCA A BOCA ON-LINE
}

Fernando Jucá Bentivegna

Mestre em Administração de Empresas pela PUC-SP e Doutorando em Administração de Empresas na FGV-EAESP.

E-mail: juca@ssj.com.br

\section{RESUMO}

O marketing boca a boca caracteriza-se pela divulgação de produtos e serviços por canais interpessoais e consiste em um componente essencial no composto de comunicação de diversas empresas. Nesse sentido, o crescimento do número de consumidores conectados à Internet motiva as empresas a buscarem caminhos para maximizar o marketing boca a boca por meio de ferramentas on-line, como o marketing viral. Com o objetivo de identificar as principais características de uma ação eficaz de marketing boca a boca virtual, realizou-se uma pesquisa exploratória com usuários de Internet em janeiro e fevereiro de 2001. Ao final, são indicados seis fatores que podem influenciar o sucesso do marketing boca a boca virtual.

ABSTRACT

Word of mouth marketing is characterized by the promotion of products and services through interpersonal

channels and is an essential component in the communication mix of many companies. Therefore, the growing number of consumers connected on-line motivates companies to search new ways to maximize word of mouth marketing through the use of virtual tools, such as viral marketing. With the intention of identifying the main characteristics of efficient virtual word of mouth marketing, an exploratory research was conducted with Internet users, during January and February of 2001. Finally, six factors are suggested to influence virtual word of mouth marketing effectiveness. 


\section{INTRODUÇÃO}

A divulgação de novos produtos e serviços por canais interpessoais é também conhecida como propaganda boca a boca (Schiffman e Kanuk, 1995, p. 395) e pode ocorrer pessoalmente, num encontro face a face, ou por meio de uma tecnologia de comunicação, como um diálogo por telefone.

Segundo Cafferky (1999, p. 8), mais de $80 \%$ das pessoas seguem as recomendações de um familiar, amigo ou um profissional ao adquirirem um produto ou serviço. Segundo esse autor, cada cliente possui uma rede de relacionamentos, sendo essa rede a principal fonte para os consumidores obterem informações sobre inovações.

\section{A DIFUSÃO DE INOVAÇÕES}

\section{ACONTECE POR INTERMÉDIO}

\section{DE DETERMINADOS CANAIS DE}

\section{COMUNICAÇÃO, O MEIO PELO QUAL}

\section{A MENSAGEM FLUI DE UM INDIVÍDUO OU ORGANIZAÇÃO PARA OUTRO.}

As empresas freqüentemente empregam técnicas para acelerar a difusão de novos produtos e serviços utilizando a propaganda boca a boca (Cuneo, 1994, p. 12). Com o surgimento e crescimento da Internet, passa-se a discutir-se como utilizar os canais interpessoais virtuais para aumentar o potencial do marketing boca a boca.

Diversos autores já estudam a importância do ambiente virtual para transmissão de mensagens entre consumidores. Segundo Kotler (1997, p. 733), por exemplo, cada vez mais, comunicações interpessoais ocorrem dentro do ambiente da Internet, em chats, fóruns ou listas de discussão em que milhares de pessoas trocam informações e opiniões sobre produtos e serviços.

Este artigo busca entender como as empresas podem maximizar o potencial de ações virtuais de marketing boca a boca. Foca-se, especialmente, em ações de marketing viral. De acordo com Graham (1999, p. 1), marketing viral significa criar mensagens virtuais que contenham conceitos absorvidos por pessoas que entrem em contato com a mensagem pela Internet. Tais mensagens devem ser poderosas o bastante para incentivarem os consumidores a passá-las adiante.

Para este estudo, foi realizada uma pesquisa exploratória mediante entrevistas pessoais com 20 consumidores com idade entre 20 e 30 anos, a fim de identificarem-se variáveis de impacto em uma ação virtual de marketing boca a boca. Os resultados dessa pesquisa su- gerem seis fatores que influenciam o sucesso dessas ações de marketing boca a boca.

\section{A DIFUSÃO POR MEIO DE CANAIS INTERPESSOAIS}

Para um novo produto ou serviço ser bem-sucedido, ele tem que se difundir e ser adotado pelo público que busca atender. Segundo Vico Mañas (1999, p. 180), o processo de difusão compreende o modo pelo qual as inovações são transmitidas e assimiladas pelo mercado.

Toda difusão de inovações acontece por intermédio de determinados canais de comunicação, sendo o canal de comunicação o meio pelo qual a mensagem flui de um indivíduo ou organização para outro (Cafferky, 1999, p. 7).

Para Rogers (1995, p. 18), os estudos nessa área tradicionalmente identificavam dois tipos de canais de comunicação: os canais de mídia de massa e os interpessoais. Os primeiros envolvem a utilização de uma mídia de massa como rádio ou televisão, significando rapidez ao possibilitar que uma única fonte atinja uma audiência de vários milhões de indivíduos. Segundo o mesmo autor, é justamente na rapidez da difusão da mensagem que reside a principal vantagem dos canais de comunicação de massa.

Por outro lado, os canais interpessoais implicam contato pessoal entre duas ou mais pessoas, nenhuma das quais apresentando um interesse comercial direto na troca de informações. Uma característica-chave da comunicação interpessoal é ser informal e acontecer entre duas pessoas que possuem outros assuntos de interesse comum.

A difusão por canais interpessoais revela-se extremamente eficiente em função de diversos fatores (Schiffman e Kanuk, 1995, p. 396) relatados a seguir.

\section{Credibilidade da fonte de informação}

A credibilidade da fonte de informação representa um fator importante para a eficiência da difusão por canais interpessoais. Isso ocorre porque a fonte é considerada imparcial e objetiva, uma vez que ela não está ligada comercialmente à empresa que promove o produto. Essa credibilidade pode originar-se também de uma experiência direta do transmissor da mensagem com o produto.

Justamente por a informação ter sua origem em fontes supostamente neutras, ela manifesta-se menos filtrada por mecanismos de percepção, como a exposição seletiva a mensagens e a dispersão de atenção, fenômenos mais comuns nas informações provenientes de campanhas de propaganda.

Nesse sentido, muitas empresas, para incentivar a propaganda boca a boca, incluem o testemunho de "personalidades famosas" ou experts em sua comunicação. O objetivo é emular o processo de comunicação interpessoal, segundo o qual alguém em que você confia recomenda um novo produto (Tripp e Carlson, 1994, p. 535). 
A ocorrência simultânea de mensagens favoráveis e desfavoráveis sobre o novo produto

A informação originada de mensagens de comunicação de massa mostra-se invariavelmente positiva em relação ao novo produto. Assim, o fato de líderes de opinião fornecerem tanto informações positivas como negativas sobre o novo produto acaba contribuindo ainda mais para a confiabilidade do processo.

Novamente, com o objetivo de simular esse processo interpessoal de difusão de inovações, diversas empresas têm incluído algumas mensagens negativas em sua comunicação publicitária. Existem, inclusive, estudos que sugerem que uma mensagem com alguma informação negativa sobre o novo produto pode ser mais efetiva que uma mensagem em que apenas aspectos positivos são apresentados (Crowley e Hoyer, 1994, p. 561).

\section{A importância da opinião \\ dos grupos de referência}

É bastante estudada a influência no comportamento do consumidor dos chamados grupos de referência. Os grupos de referência podem ser formados por grupos de amigos ou membros da família. Alguns modelos, por exemplo, que tentam prever o comportamento do consumidor, baseiam-se, essencialmente, em dois fatores: a consequiência imaginada pelo consumidor para o seu ato e o que ele acredita que será a opinião dos seus grupos de referência sobre o seu ato (Jagdish, Gardner e Garret, 1994, p. 122).

Todos os fatores apresentados são responsáveis pela eficiência dos canais interpessoais. Os canais de mídia de massa, no entanto, ainda são muito utilizados pelas empresas em função da necessidade de acelerar o processo de difusão da inovação.

A novidade dos últimos anos - o surgimento da Internet -, contudo, desenvolve um terceiro tipo de canal de comunicação: o virtual. Um canal que permite a velocidade dos canais de mídia de massa, pois as mensagens são transmitidas na velocidade da luz, e a interação de milhões de consumidores de forma interpessoal.

Dessa maneira, a Internet abriu um novo e vasto campo de pesquisa para teóricos de marketing interessados em entender o fenômeno de difusão pela Internet. Segundo Sterne e Priore (2000, p. 8), a pesquisa em torno do tema difusão pela Internet ainda é uma área pouco explorada, mas necessita receber grande atenção nos próximos anos em razão da necessidade de as empresas divulgarem seus produtos e serviços de forma mais eficiente.

\section{REDES INVISÍVEIS}

A Internet impõe um novo modo de pensar ao profissional acostumado a lidar com redes reais em que as ligações entre os nodos são conexões físicas, como os trilhos de um trem. Nas redes virtuais, por outro lado, as ligações entre os nodos são invisíveis, embora sejam absolutamente fundamentais para a dinâmica do mercado.

Ao mesmo tempo, atualmente, o desafio das empresas em tornar seus produtos conhecidos é grande. O problema reside em como destacar a mensagem de um produto específico entre tantas informações e mensagens publicitárias recebidas diariamente pelos consumidores. Wurman (1990, p. 23) cita um bom exemplo desse fenômeno de sobrecarga de novos conteúdos quando afirma que uma edição diária do jornal New York Times contém, normalmente, mais informação do que uma pessoa comum iria encontrar durante toda sua vida, durante o século XVII, na Inglaterra. Rosen (2000, p. 14) menciona ainda que profissionais de comunicação estimam que uma pessoa que more em uma grande cidade pode receber mais de 1.500 diferentes mensagens publicitárias todos os dias.

\section{A INTERNET DESENVOLVE UM}

\section{TERCEIRO TIPO DE CANAL DE} COMUNICAÇÃO QUE PERMITE A
VELOCIDADE DOS CANAIS DE MÍDIA

\section{DE MASSA E A INTERAÇÃO DE MILHÕES DE CONSUMIDORES.}

Uma rede interpessoal de contatos ajuda os indivíduos a lidarem com a incerteza relativa a novos produtos e idéias e a aliviar a tensão causada por experiências muito positivas ou negativas com o produto. Rosen (2000, p. 41), por exemplo, cita uma pesquisa que indica que compradores on-line contam suas experiências de consumo na Internet para outras 12 pessoas. Na média, essa pessoa acaba falando com 3,2 familiares próximos, 2 parentes distantes, 3,3 amigos, 2,5 colegas de trabalho e outros 1,3 "conhecidos".

Cada pessoa tem sua própria rede de contatos. São amigos, colegas de trabalho ou familiares com quem costuma conversar e trocar informações. Segundo Dunbar (1996, p. 76), cientistas da comunicação delinearam três níveis distintos de redes de contato. Num nível mais básico, estão entre 10 ou 12 pessoas, que representam as pessoas mais próximas de cada indivíduo. Um indicador é que essas são pessoas cujo falecimento provocaria um efeito devastador no indivíduo pesquisado. Num nível intermediário de contatos, estariam outras aproximadamente 150 pessoas, com as quais se tem um genuíno relacionamento social. O indicador-chave aqui re- 
vela que essas são pessoas que o indivíduo pesquisado não se sentiria desconfortável em convidar para sua casa. Finalmente, existe um terceiro nível, com até cerca de 1.500 pessoas, de meros conhecidos, com os quais os indivíduos pesquisados raramente, ou apenas em ocasiões específicas, mantinham algum contato.

\section{MARKETING VIRAL ABRANGE}

\section{O PLANEJAMENTO E A EXECUÇÃO DE AÇÕES QUE TÊM COMO} OBJETIVO PRINCIPAL ESTIMULAR

\section{O MARKETING BOCA A BOCA}

\section{DA EMPRESA PELA INTERNET.}

É fundamental entender que é por meio dessas redes de contatos que a informação viaja pelo mundo todo e, por intermédio delas, o boca a boca sobre um novo produto difunde-se, até representar um dos principais fatores para a decisão de adotar ou não uma inovação, como relatado a seguir (Rosen, 2000, p. 5):

- $77 \%$ dos norte-americanos pedem um conselho para seus conhecidos antes de escolher um novo médico.

- $65 \%$ dos consumidores que compraram uma agenda eletrônica afirmaram terem tomado conhecimento do novo produto por um conhecido.

- Amigos e parentes são a principal fonte de informação sobre novos lugares para visitar, hotéis e passagens aéreas.

Ainda sobre as redes de contatos, desenvolveu-se a teoria dos elos fracos. Segundo Rogers (1995, p. 309), uma pessoa tem mais chance de adquirir novas informações por meio de contatos com indivíduos de outras redes de contatos. Isso acontece porque os amigos próximos de uma pessoa raramente sabem alguma coisa que ela mesma já não saiba. Geralmente, os amigos íntimos de uma pessoa são amigos uns dos outros, formando uma rede fechada, que tende a ser extremamente ineficaz como fonte de novas informações sobre o ambiente externo. Muito mais útil para acessar novas informações são os conhecidos mais distantes ou elos fracos. Por exemplo: o site www.conquistador.com.br conduziu uma pesquisa com 200 jovens profissionais que conseguiram emprego por intermédio de contatos pessoais. Apenas $22 \%$ desses contatos eram de amigos próximos ou parentes, considerados elos fortes, sendo o restante de conhecidos distantes ou encontros ocasionais, os chamados elos fracos.

O crescimento dos elos fracos com a Internet está na essência da explicação do porquê a informação, hoje, circula muito mais rapidamente. Na verdade, a Internet cria milhões de atalhos por meio de elos fracos que acabam ligando diferentes redes de contatos ao redor do mundo. Há alguns anos, existiam diversas informações e novidades que não justificavam uma chamada telefônica para amigos distantes, por exemplo. Mas, atualmente, em poucos segundos, pode-se enviar uma mensagem por e-mail para conhecidos espalhados em diversos países.

\section{MARKETING VIRAL}

Segundo Sterne (2000, p. 6), marketing viral abrange o planejamento e a execução de ações que têm como objetivo principal estimular o marketing boca a boca da empresa pela Internet, aproveitando-se das redes virtuais de contato.

De acordo com Graham (1999, p. 2), desenvolver uma campanha de marketing viral pode ser muito difícil. Mas, se for criada uma mensagem, desde um simples texto até algo que envolva a tecnologia de todo um site, que motive as pessoas a passarem sua comunicação adiante pela Internet e que suporte os benefícios de sua marca, então, existem todas as chances de sucesso.

Um exemplo premiado de marketing viral foi o desenvolvido pela Procter \& Gamble para seu produto Scope Mouthwash, um produto para higienização e melhora do hálito bucal. A Procter \& Gamble desenvolveu uma mensagem personalizada que permitia aos consumidores reproduzirem "beijos virtuais" para seus amigos. Assim, ao mesmo tempo em que a mensagem reforçava o conceito de marca da Scope, que era "fale tão perto quanto um beijo", existia um mecanismo que incentivava a difusão da mensagem pelo mundo virtual. De fato, a Procter $\&$ Gamble tinha a tecnologia para acompanhar as mensagens e confirmou que, em pouco tempo, existiam "beijos virtuais" circulando em todo o mundo, o que significou um aumento posterior da imagem da marca da empresa e da intenção de compra dos consumidores-alvo da marca (Graham, 1999, p.1).

Os cartões virtuais representam outro exemplo de marketing viral interessante. Nesse caso, a mecânica viral é a seguinte: o site disponibiliza uma série de cartões, que podem ser gratuitamente enviados on-line por qualquer pessoa. Além de ser gratuito, o usuário do site sente-se motivado a enviar os cartões em função de eles representarem uma maneira prática e rápida de mostrar para um amigo a lembrança de uma data especial. Cada cartão enviado pelo usuário para um amigo leva junto o endereço do site patrocinador do cartão, marcando, então, a presença da empresa na mensagem.

Existem algumas variações na utilização de cartões virtuais:

- sites como www.yahoo.com.br permitem que o usuário personalize o texto da mensagem do cartão;

- sites como www.emotioncards.com.br registram o 
endereço do recebedor do cartão, o qual, posteriormente, é abordado com mensagens sugerindo que ele também envie cartões para seus amigos.

Mas, apesar dessas pequenas diferenças de execução, a essência do processo revela-se a mesma: uma pessoa recebe um cartão e gosta da experiência. Depois, ela envia o mesmo cartão para outros amigos, que, em seguida, enviam para outros amigos e assim por diante. Cada um desses cartões virtuais sempre carrega a mensagem do site que desenvolveu o cartão.

A partir dessa discussão, a pergunta que se elabora é: Quais são os elementos que contribuem para a eficácia de uma ação virtual de marketing boca a boca?

\section{A PESQUISA}

Objetivando responder à pergunta acima, foi realizada uma pesquisa exploratória com 20 usuários de Internet, em janeiro e fevereiro de 2001. De acordo com Koche (1999, p. 126), recomenda-se a pesquisa exploratória quando se pretende levantar possíveis variáveis sobre o fenômeno que se quer estudar, o que constitui justamente o objetivo deste estudo.

A amostra dessa pesquisa foi selecionada por conveniência entre jovens profissionais da cidade de São Paulo, com idade entre 20 e 30 anos. Segundo a pesquisa Cadê/ Ibope de março de 2001, essa faixa etária representa 53\% dos usuários brasileiros de Internet. Na cidade de São Paulo, residem $22 \%$ dos usuários brasileiros de Internet.

Para cada entrevistado, perguntou-se: "Qual a mensagem comercial que você recebeu pela Internet e replicou, também pela Internet, para o maior número de pessoas?" Foi, então, realizada uma entrevista pessoal não-estruturada de 60 minutos, em que foram questionados os principais motivos que levaram o entrevistado a replicar a mensagem.

Para os motivos mencionados, no final da entrevista, foi solicitado que cada entrevistado classificasse o motivo como pouco importante, importante ou muito importante.

\section{ANÁLISE DE RESULTADOS}

Como este estudo é exploratório, tem-se como objetivo principal fornecer variáveis que possam ser medidas em futuros estudos descritivos. Serão analisadas as características comuns nas ações de marketing viral mencionadas pelos entrevistados. Como característica comum, determinou-se que pelo menos metade dos entrevistados deveria apresentar a característica como importante ou muito importante.

Analisou-se, a seguir, uma relação de seis fatores potencialmente importantes para o sucesso do marketing boca a boca virtual.
Familiaridade com a marca da empresa que realiza a ação de marketing viral

Todas as mensagens virtuais discutidas nas entrevistas eram originadas por empresas que os entrevistados já conheciam por outros meios. Observou-se que a familiaridade com a marca da empresa atua como um inibidor do receio do usuário em replicar mensagens enganosas. Como disse um entrevistado: "Qualquer empresa pode fazer uma promoção pela Internet. Fica difícil separar as

\section{NA PESQUISA REALIZADA, OS}

\section{ENTREVISTADOS APONTARAM}

\section{A IMPORTÂNCIA DE ASPECTOS \\ LÚDICOS E DE ENTRETENIMENTO \\ PARA O SUCESSO DE CAMPANHAS}

\section{DE MARKETING VIRAL.}

promoções sérias daquelas realizadas por empresas não confiáveis. É muito difícil controlar isso na Internet... Assim, só retransmito uma mensagem quando ela é de uma empresa conhecida e respeitada."

\section{Desenvolvimento de uma massa crítica de amplificadores da mensagem}

Detectou-se que o recebimento da mensagem de diferentes fontes, além da empresa originadora, aumentava o potencial de que a mensagem fosse replicada. Segundo um entrevistado: "Eu recebi aquela mensagem de três amigos diferentes, num intervalo de apenas uma semana. Tive, então, a impressão de que era algo realmente quente e importante e que eu devia passar a mensagem adiante."

Nesse sentido, parece que, quanto maior o número inicial de pessoas dispostas a retransmitirem uma mensagem virtual, mais veloz é a sua propagação pela Internet. Desta forma, o desafio do profissional de marketing consiste em cativar uma quantidade inicial de usuários que, pelo seu perfil e hábitos de consumo, podem ser potenciais amplificadores virtuais da mensagem da empresa.

Exemplo de utilização desse conceito é o site www.arremate.com.br e seu enfoque inicial no leilão de produtos conhecidos como sendo de colecionadores, caso dos selos, latinhas de cerveja ou adesivos. A lógica subjacente a essa iniciativa indica que essas pessoas já estavam acostumadas a transacionar e comercializar os itens de sua coleção fora da WEB e, portanto, teriam interesse mais imediato nos leilões virtuais como forma de expandir suas coleções. Depois, além desse público-alvo, foram focados os adeptos e entusiastas de inovações tec- 
nológicas, por meio da oferta de diversos produtos de informática, pois esse público teria menos receio e mais aptidão para efetuar transações comerciais na Internet. Essa estratégia teve um ótimo resultado, já que esses dois perfis de usuário realmente representaram as primeiras pessoas a utilizar o Arremate e serviram como fonte de referência para os futuros usuários do site.

\section{Baixa complexidade da mensagem}

Complexidade é o grau em que uma inovação ou mensagem sobre a inovação é percebida como relativamente difícil de entender e utilizar (Rogers, 1995, p. 242). As entrevistas para este estudo sugerem que, quanto maior a sua complexidade, menor tende a ser a rapidez com que a mensagem on-line se difunde.

Lidar com a complexidade na Internet está intimamente relacionado com facilitar a navegação, pela clareza das informações e utilização de recursos gráficos (Zimmerman, 2000, p. 114). Assim, a mensagem virtual, apesar de toda tecnologia que pode estar envolvida, deve remeter a imagens familiares a todo usuário. Um bom exemplo desse conceito é o site www.amazon.com, que simplifica ao máximo a compreensão do processo de compra digital pela utilização de conceitos e símbolos tradicionais, como o de "encher o carrinho de compras" e o do "check out do pedido".

\section{Existência de incentivos}

\section{para a replicação da mensagem}

A aceleração da difusão da mensagem virtual pode ser também atingida pela oferta de algum tipo de incentivo para a replicação da mensagem. Conforme um dos entrevistados relatou: "Acho muito importante a empresa oferecer alguma compensação para eu ajudar a divulgála. É claro que um brinde é bom. Mas até mesmo algum tipo de agradecimento já ajuda."

Apesar da ampla utilização, a desvantagem apontada na implementação de incentivos monetários reside em que eles podem atrair consumidores menos fiéis, que tenderiam a descontinuar o uso do novo produto assim que terminasse a oferta dos incentivos (Newell, 2000, p. 34).

Um modelo de incentivo financeiro na Internet abrange o de comissionamento ou os chamados affiliate programs. A idéia básica desse modelo é simples: se a recomendação de um consumidor puder ajudar o negócio da empresa, então, a empresa paga uma comissão por essa indicação. O site www.livrariacultura.com.br, por exemplo, paga uma comissão de $4 \%$ para qualquer site que enviar um comprador para um de seus livros. O site que quiser se afiliar a esse programa deve apenas registrar um link e um código para a conferência da fonte da indicação e do total de comissões devido.

Godin (2000, p. 58) ainda aponta que, além dos incentivos financeiros, a maioria dos sites com programas de afiliação de sucesso conta com um outro ingrediente para acelerar sua difusão: a divulgação do nome das pessoas que mais tiveram sucesso em indicar compradores e ganhar comissões. Assim, todos têm a certeza de que o esquema de comissionamento funciona e o incentivo para continuar participando do programa. Os vencedores sentem-se ainda mais entusiasmados, tendo mais um motivo para compartilhar sua história de sucesso dentro da sua rede de contatos.

Como incentivos não financeiros, essa pesquisa apontou também o uso freqüente de brindes e presentes. Nesse modelo, um exemplo foi uma promoção do site www.arremate.com.br, apoiada por um mecanismo viral de "indique 3 amigos on-line e ganhe um CD".

Essa foi uma típica promoção viral, pois qualquer pessoa que recebesse o $e$-mail poderia participar, sendo, então, incentivada a continuar repassando a mensagem para seus próprios contatos. Além disso, a pessoa que mais indicasse amigos em toda a promoção receberia como prêmio extra um microcomputador, tendo o vencedor indicado 375 amigos.

\section{Componente de diversão da mensagem}

"Gosto de jogos, concursos, adivinhações, fatos engraçados... tudo que me convida a rir e jogar atrai o meu interesse... E me estimula a compartilhar a mensagem com um amigo."

Os entrevistados apontaram a importância de aspectos lúdicos e de entretenimento para o sucesso de campanhas de marketing viral. Um exemplo desse tipo de campanha foi a desenvolvida pela Yoyodyne Entertainments para uma companhia de consultores tributários denominada H\&R Block, que gerou mais de 46 mil potenciais clientes em apenas dez semanas de execução.

A campanha começava com banners espalhados em sites populares da WEB com o texto: "Clique aqui se você quiser que H\&R pague seus impostos." Se o consumidor clicasse no banner, seria convidado a deixar seu e-mail. Desse ponto em diante, Yoyodyne usava o endereço eletrônico das pessoas para enviar perguntas sobre impostos na forma de uma espécie de concurso com direito a prêmios. As respostas para essas perguntas eram naturalmente encontradas no site da H\&R, estimulando as pessoas a conhecerem mais sobre a empresa e possibilitando que a empresa também soubesse mais sobre esses potenciais consumidores (Lewis e Bridger, 2000, p. 117).

Lewis e Bridger (2000, p. 118) apontam esse componente de diversão como um importante componente adicional para atrair a experimentação dos consumidores: "Se além de ser prático e oferecer uma vantagem financeira, as empresas pudessem oferecer uma genuína quantidade de divertimento, então, o envolvimento do consumidor e o sucesso dos seus produtos e serviços seriam praticamente certos."

Nesse espírito, o site www.e-trading.com está trans- 
formando a indústria de serviços financeiros, ao atrair cada vez mais consumidores que investem e se divertem com o mercado financeiro a partir da sua própria casa. Mais do que os lucros que eles possam auferir, a satisfação advirá do divertimento de realizar operações financeiras on-line (Wolf, 1999, p. 43).

É como afirma Wolf (1999, p. 44) em seu livro sobre a Economia do Entretenimento: "Os consumidores descobrem que a E-Trading é divertida. Certamente mais divertida que chamar seus agentes financeiros e depois ficarem esperando. A E-Trading é como um jogo, com a emoção de decidir a partir das notícias da imprensa, e o prazer de poder sozinho empreender ações que podem afetar seu futuro financeiro pessoal."

Outro exemplo, além do E-Trading, é o que alguns autores literários estão tentando: convidar os próprios leitores a editarem seus livros. A autora norte-americana Lisa Scottoline, meses antes da publicação do seu novo best-seller, colocou o primeiro capítulo do seu livro na Internet, convidando milhares de leitores a sugerirem correções e alterações no texto. Além do retorno em publicidade gratuita, essa iniciativa claramente está alicerçada no conceito de "prazer em escrever um livro", incentivando uma experimentação do trabalho da autora (Lewis e Bridger, 2000, p. 119).

\section{Ineditismo da ação de marketing viral}

Todas as ações mencionadas nas entrevistas continham, de alguma forma, uma idéia inédita de transmitir a mensagem.

Por exemplo, uma das pessoas entrevistadas narrou a ação de marketing viral realizada pelo site da Yahoo! nos Estados Unidos. Nessa ação, um mês antes do Dia dos Namorados, personalidades famosas dos Estados Unidos foram convidadas a produzir um cartão especial com "um beijo particular". Esses cartões eram reais, únicos para cada personalidade, e seriam leiloados no site da Yahoo! no Dia dos Namorados, com a renda totalmente revertida para instituições assistenciais. Dezenas de astros participaram do evento. Cartões, como o do cantor inglês Elton John, chegaram a ser leiloados por 7 mil dólares.

Fica claro que esse tipo de ação gera uma série de comentários e reforça diversos conceitos positivos do Yahoo!, até pela orientação da iniciativa a uma causa humanitária. Contribui-se, assim, para o interesse e entusiasmo do público. A difusão viral vem no momento seguinte, quando o Yahoo! disponibiliza gratuitamente modelos virtuais dos "cartões com beijo" de cada um dos astros. Aí, então, milhões de pessoas passam a compartilhar esses cartões e essa "história" pela Internet.

\section{CONCLUSÃO}

Alguns autores, como Dye (2000, p. 142), afirmam que uma campanha boca a boca de sucesso pode e deve ser pla- nejada. Além disso, segundo o mesmo autor, a imensa maioria das indústrias lida com produtos cujas vendas podem ser influenciadas pelo marketing boca a boca e, portanto, erra ao não trabalhar essa possibilidade de comunicação.

Já outros autores, como Austin (1998, p. 25), defendem a tese de que ainda é necessária uma grande dose de sorte e imponderável combinação de fatores favoráveis para que a mensagem boca a boca contagie o mercado consumidor. Dessa forma, seria extremamente difícil efetivamente planejar uma campanha viral.

\section{UMA VANTAGEM IMPORTANTE}

\section{DO MARKETING VIRAL É O}

\section{POTENCIAL DE DIMINUIR O RISCO}

\section{QUE O CONSUMIDOR ASSOCIA}

\section{AO PROCESSO DE COMPRAR}

\section{DETERMINADO PRODUTO.}

Este artigo pretende mostrar que, apesar da presença de determinados fatores incontroláveis, aliás atuantes em qualquer processo de comunicação empresarial, existem, no entanto, pelo menos seis fatores que, aparentemente, influem positivamente no sucesso de uma campanha viral.

Tanto pelas entrevistas como pela análise da bibliografia pesquisada para este estudo, notou-se que parece existir um movimento para valorizar a realização de campanhas de marketing boca a boca de produtos e serviços com a utilização dos canais on-line. Na verdade, a Internet possibilita um novo método para as empresas se comunicarem com os consumidores.

Nas décadas de 70 e 80 , ocorreu o auge da mídia de massa, quando o fluxo era de um (a empresa) para muitos (os consumidores). Já na década de 90, ganhou força o conceito de marketing um (a empresa) para um (cada consumidor). Talvez agora, no início de uma nova década, esteja-se assistindo ao crescimento de um novo modelo de fluxo de comunicação: o de muitos (vários consumidores) para muitos (outros vários consumidores), possível pelas ações que potencializam o marketing boca a boca virtual.

Nesse novo modelo, o objetivo do marketing seria "estimular" os consumidores com uma mensagem poderosa e envolvente, passível de ser passada adiante pelo boca a boca. A inteligência desse modelo é que são os próprios consumidores que acabam divulgando a empresa para outros consumidores.

Outra vantagem importante do marketing viral consiste em que o aumento do número de mensagens on-line recebidas de diferentes pessoas tem o potencial de diminuir o risco que o consumidor associa ao processo de com- 
prar determinado produto. Na verdade, diversos pesquisadores já revelaram que, na tentativa de lidar com o risco, os consumidores têm seu comportamento e percepções significativamente influenciados pelo comportamento e percepções de outras pessoas (Grewel, Gotlieb e Marmorstein, 1994, p. 151).

Além disso, ao tentar lidar com o risco, uma das principais estratégias adotadas por consumidores é buscar ativamente novas informações por meio de relações interpessoais (Dowling e Staelin, 1994, p. 125), o que, por sua vez, teria a conseqüência de alimentar positivamente o processo do marketing viral e a transmissão das mensagens on-line.

Esse conjunto de fenômenos mostra-se particularmente relevante para empresas cujas receitas advêm de transações on-line, já que, de acordo com Clancy e Krieg (2000, p. 232), o principal benefício que os consumidores buscam em um site de comércio eletrônico é a convicção de que o site é confiável e possui todos os elementos para garantir a segurança do processo de compra.

Mas, a despeito desse cenário, o desenvolvimento de campanhas de marketing viral realmente eficientes ainda impõe pelo menos dois desafios às empresas. $\mathrm{O}$ primeiro desafio concerne à complexidade da administração de uma campanha de marketing viral.

É, por um lado, verdade que o marketing viral não necessita de mecanismos complexos para ser eficiente. Como afirma Rosen (2000, p. 22): "Os fundadores da empresa Hotmail, que oferece um serviço gratuito de $e$ mails, claramente entenderam o princípio da simplicidade. A empresa fez dos seus consumidores iniciais o seu principal divulgador ao colocar, no final de toda e cada mensagem enviada por seus usuários, o texto 'Get your free $e$-mail at Hotmail' (obtenha seu $e$-mail gratuito na Hotmail). O resultado foi que, nos primeiros 18 meses do negócio, a Hotmail conseguiu mais de 12 milhões de usuários para seus serviços. Apenas para comparar, a AOL, líder do mercado norte-americano de provedores da Internet, demorou mais de 6 anos para atin- gir o mesmo número de assinantes."

Por outro lado, com este artigo, procurou-se ilustrar que não é tão simples a realização de campanhas de marketing viral de sucesso. Além do desafio criativo de criar mensagens virtuais inéditas e divertidas, é importante que a empresa tenha um entendimento profundo dos seus consumidores, para melhor administrar aspectos como relevância e complexidade da mensagem. Atualmente, essa compreensão do comportamento dos consumidores pode ser baseada em dados matemáticos, como a porcentagem de potenciais consumidores que acessaram o site da empresa após determinada mensagem. Mas o grande obstáculo para que essas informações sejam realmente utilizadas advém menos de ausência de tecnologia disponível e muito mais da falta de uma disposição gerencial de buscar novas formas de administrar o relacionamento com os consumidores (Sheth e Parvatiyar, 2000, p. 526).

A necessidade de coordenar um esforço de comunicação integrado representa outro desafio importante para as empresas. Este estudo sugere que o grau de conhecimento da marca pode influenciar na eficiência da campanha de marketing viral. Clancy e Krieg (2000, p. 238) chegam a cunhar a expressão spiral branding para ações coordenadas entre mídias tradicionais, que trabalham o conhecimento de marca, e ações por intermédio de $e$-mails, que visam à difusão da mensagem da empresa pela Internet.

Para futuros trabalhos acadêmicos, recomenda-se a realização de um estudo descritivo que permita mensurar o real impacto de cada um dos fatores apresentados no sucesso de ações de marketing boca a boca virtual.

Seria interessante também estudar toda a evolução de campanhas de marketing viral, para verificar como as empresas brasileiras mensuram os resultados dessas ações, gerenciam todo o processo de comunicação e utilizam as novas informações adquiridas para desenvolvimento de novas campanhas.

De qualquer forma, espera-se que este artigo incentive a discussão dessa nova possibilidade de comunicação entre a comunidade empresarial e a acadêmica. $\bigcirc$

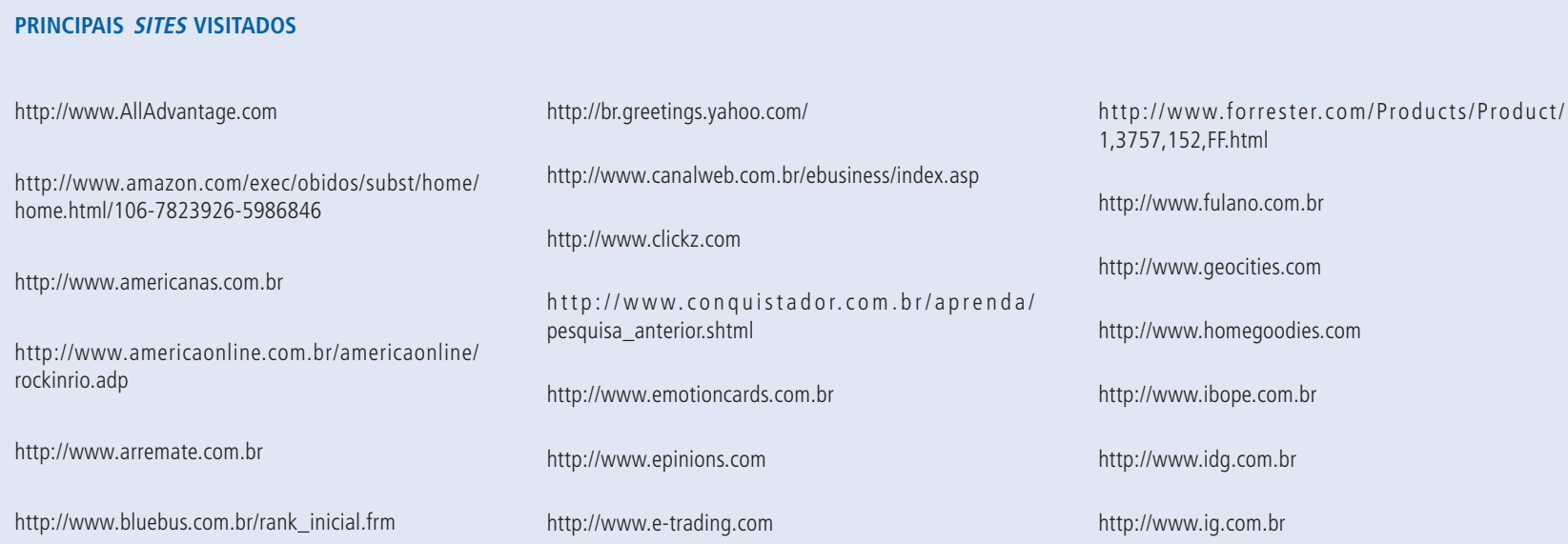

http://br.greetings.yahoo.com/

http://www.canalweb.com.br/ebusiness/index.asp

http://www.clickz.com

http://www.conquistador.com.br/aprenda/ pesquisa_anterior.shtml

http://www.emotioncards.com.br

http://www.epinions.com

http://www.e-trading.com

http://www.forrester.com/Products/Product/ 1,3757,152,FF.html

http://www.fulano.com.br

http://www.geocities.com

http://www.homegoodies.com

http://www.ibope.com.br

http://www.idg.com.br

http://www.ig.com.br 
http://www.hotmail.com

http://mkteam.com.br/Principal1.htm

http://www.mp3.com http://www.mypoints.com

http://www.priceline.com/telecomeasyhelp.asp? session key=050111ACD000 11AC200011221426 03292961707546\& Customertype=Student http://www.yahoo.com.br

http://www.1 to1.com.br

http://200.212.77.104/mmonline/jsp/Navega.jsp? pldMenuConteudo $=678$

\section{BIBLIOGRAFIA}

AUSTIN, Nancy. In search of buzz. Incentive, v. 172, p. 25-26, Oct. 1998.

BRIGGS, Rex, HOLLIS, Nigel. Advertising on the Web; is there response before click-through? Journal of Advertising Research, v. 37, n. 2, p. 33-45, Mar. 1997.

BRONDMO, Hans Peter. The engaged customer. New York : Harper Collins, 2000

BURNETT, John, MORIARTY, Sandra. Marketing communications. New Jersey : Prentice Hall, 1998.

CAFFERKY, Michael. Venda de boca a boca: deixe seus clientes fazerem a propaganda. São Paulo : Nobel, 1999.

CAROPRESO, Percival. Laboratório de marketing. São Paulo : Nobel, 1998

CLANCY, Kevin, KRIEG, Peter. Counter-intuitive marketing. New York : Free Press, 2000.

CROWLEY, Ayn, HOYER, Wayne. An integrative framework for understanding two-sided persuasion. Journal of Consumer Research, v. 20, p. 561-572, Mar. 1994.

CUNEO, Alice. Starbucks' word-of-mouth wonder. Advertising Age, p. 12, Mar. 1994.

DAWKINS, Richard. O gene egoísta. Belo Horizonte : Itatiaia, 1989.

DOWLING, G., STAELIN, R. A model of perceived risk and intended risk-handling activity. Journal of Consumer Research, v. 21, p. 119-134, June 1994.

DUNBAR, Robin. Grooming, gossip, and the evolution of language. Cambridge : Harvard University Press, 1996.

DYE, Renée. The buzz on buzz. Harvard Business Review, v. 78, n. 6, p. 139-146, Nov. 2000

GODIN, Seth. Unleashing the idea virus. New York : Do You Zoom, 2000.

GRAHAM, Jeffrey. What does viral marketing really mean? [10-11-1999]. Disponivel na Internet: <http:// www.clickz.com/mkt/emkt_strat/article.php/817461>.

GRANITZ, Neil, WARD, James. Virtual community: a sociocognitive analysis. Advances in Consumer Research, v. 23, p. 161-166, 1996.
GREWEL, D., GOTLIEB, J., MARMORSTEIN, H. The moderating effects of message framing and source credibility on the price-perceived risk relationship. Journal of Consumer Research, v. 21, p. 145-153, June 1994.

HARTMAN, Amir, SIFONIS, John. Pronto para a web. Rio de Janeiro : Campus, 2000

HOWARD, John, SHETH, Jagdish. The theory in marketing behavior. New York : Wiley, 1969.

JAGDISH, Sheth, GARDNER, David M., GARRET, Dennis E. Marketing theory: evolution and evaluation. New York Wiley, 1994.

JANAL, Daniel. Online marketing handbook. New York International Thompson, 1995.

JONASH, Ronald S., SOMMERLATTE, Tom. The innovation premium. Massachusetts : Perseu Books, 1999.

KANIA, Deborah. Measuring one-to-one efforts. [2-91999]. Disponivel na Internet: <http://www.clickz.com/ article.php/813341>.

KARSAKLIAN, Eliane. Comportamento do consumidor. São Paulo : Atlas, 2000

KOCHE, José Carlos. Fundamentos da metodologia científica. 15. ed. Rio de Janeiro : Vozes, 1999.

KOTLER, Philip. Marketing management. New Jersey Prentice-Hall, 1997.

LEWIS, David, BRIDGER, Darren. The soul of the new consumer. London : Nicholas Brealey, 2000.

LOWY, Alex, TAPSCOTT, Don, TICOLL, David. Digital capital. Boston : Harvard Business School Press, 2000.

MACPHERSON, Kim. Features that click. [11-6-2000] Disponivel na Internet: <http://www.clickz.com/em_mkt/ em_mkt/article.php/831771>.

MANASCO, Britton. The transformation of the selling process. [2-1997].Disponivel na Internet: <http:// www.webcom.com/quantera/Selling.html>.

MISNER, Ivan R., DEVINE, Virginia. The world's best known marketing secret. Austin : Bard Press, 1999.

MITROFF, Ian. Tempos difíceis, soluções inovadoras. Rio de Janeiro : Campus, 1999.

NEWELL, Frederick. Fidelidade.com. São Paulo : Makron Books, 2000.
NEWMAN, Peter. When windows replace walls: investigating virtual word-of mouth exchanges and constructing multilogue profiles. Advances in Consumer Research, v. 26, p. 653-654, 1999.

RICHINS, Marsha L. Negative word-of-mouth by dissatisfied consumers: a pilot study. Journal of Marketing, v. 47, p. 68-78, Winter 1983

ROGERS, Everett. Diffusion of innovations. New York: Free Press, 1995

ROSEN, Emanuel. The anatomy of buzz: how to create word of mouth. New York: Doubleday, 2000.

SCHIFFMAN, Leon, KANUK, Leslie. Consumer behavior. New Jersey: Prentice Hall, 1995.

SEYBOLD, Patricia. Customers.com: how to create a profitable business strategy for the Internet and beyond. New York : Random House, 1998.

SHETH, Jagdish, PARVATIYAR, Atul. Handbook of relationship marketing. Thousand Oaks : Sage, 2000.

STERNE, Jim, PRIORE, Anthony. E-mail marketing. New York : John Wiley \& Sons, 2000

STEUER, Jonathan. Defining virtual reality: dimensions determining telepresence. Journal of Communication, v. 42, n. 4, p. 73-93, Autumn 1992

TAPSCOTT, Don. Economia digital. São Paulo : Makron Books, 2000.

TRIPP, Carolyn, CARLSON, Les. The effects of multiple product endorsements by celebrities on consumers attitudes and intentions. Journal of Consumer Research, v. 20, p. 535-547, Mar. 1994.

USBORNE, Nick. The three rules of permission. [24-72000]. Disponivel na Internet: <http://www. clickz.com/ mkt/permis_mkt/article.php/826781>

VASSOS, Tom. Marketing estratégico na Internet. São Paulo : Makron Books, 1998

VICO MAÑAS, Antonio. Gestão de tecnologia e inovação. São Paulo : Érica, 1999.

WOLF, Michael. The entertainment economy. New York : Times Books, 1999.

WURMAN, Richard Saul. Information anxiety. New York : Doubleday, 1990

ZIMMERMAN, Jan. Marketing on the Internet. 4. ed. Florida : Maximum Press, 2000 